\title{
Yellow bodies in superficial and deep lymph nodes
}

\author{
A. J. C. TUDWAY \\ From the Department of Pathology, Medical School, University of Bristol, University Walk, \\ Bristol BS8 ITD, UK
}

SUMMARY The prevalence of yellow bodies was studied in superficial and deep lymph nodes in material from 46 necropsies. They were found in $22.8 \%$ of the 359 lymph nodes collected, ranging from $35.6 \%$ of the mesenteric to $11.1 \%$ of mediastinal lymph nodes, and were significantly more prevalent in deep abdominal than in superficial groups. Sets of lymph nodes from individuals tended to show an 'all or none' variation in the proportion of nodes that contained yellow bodies, but the presence of the bodies was not significantly related to age, sex, or disease.

Yellow bodies (syn. yellow-brown bodies, HamazakiWesenberg bodies) are small, spindle-shaped structures of unknown significance, which are found principally in the sinuses of lymph nodes, either within the cytoplasm of histiocytes or lying free. They have histochemical properties similar to lipofuscin (Sieracki and Fisher, 1973), and ultrastructural studies have suggested that they are probably giant lysosomal residual bodies (Doyle et al., 1973). They were first described by Hamazaki in 1938, and interest in them was aroused by reports of their presence in lymph nodes from patients with sarcoidosis (Wesenberg, 1966; Vira et al., 1968), though others have found them in a variety of conditions (Boyd and Valentine, 1970), and recently their occurrence in association with melanosis coli has been reported (Hall and Eusebi, 1978). The purpose of this study is to investigate the prevalence of yellow bodies in a series of necropsies to determine whether this varies in different lymph node groups and whether they are associated with any particular type of disease.

\section{Material and methods}

One lymph node was sought from each of the eight sites listed in Table 1 in cases chosen at random at necropsy. The largest lymph node in each group was taken, and those cases in which at least seven lymph nodes could not be found or in which they were totally replaced by tumour were omitted from the study; 359 lymph nodes were collected from 26 males and 20 females (mean age $63 \cdot 4$, range 11-84, years), the main causes of death being listed in Table 2 .

Received for publication 26 June 1978
Table 1 Prevalence of yellow bodiés in the different lymph node groups studied

\begin{tabular}{lrll}
\hline Lymph node group & \multicolumn{3}{l}{ Lymph nodes } \\
\cline { 2 - 4 } & No. & No. with YBs & Per cent with YBs \\
\hline Axillary & 46 & 9 & $19 \cdot 6$ \\
Inguinal & 46 & 6 & $13 \cdot 0$ \\
Mediastinal (paratracheal) & 45 & 5 & $11 \cdot 1$ \\
Lesser curve & 45 & 10 & $22 \cdot 2$ \\
Porta hepatis & 46 & 13 & $28 \cdot 3$ \\
Cystic & 43 & 12 & $27 \cdot 9$ \\
Mesenteric & 45 & 16 & $35 \cdot 6$ \\
Para-aortic & 43 & 11 & $25 \cdot 6$ \\
Totals & 359 & 82 & 22.8 \\
\hline
\end{tabular}

YB = yellow body

After fixation in $10 \%$ buffered formol saline and conventional processing, two paraffin sections from each lymph node were stained with haematoxylin and eosin and hexamine silver (Drury and Wallington, 1967) respectively. The pairs of sections were given accession numbers and randomised to conceal both the site and case from which they came. The hexamine silver stain was used for initial screening as most yellow bodies have reducing properties (Fig. 1). Final identification was made on the $\mathrm{H}$ and E section in which they appear as yellow or brown, smoothly outlined, round or oval structures, frequently pointed at one or both ends and often with a central unstained or vacuolated zone. No structure less than $2 \mu \mathrm{m}$ in length was accepted since bodies of this size are difficult to distinguish from similarly staining but irregularly shaped granules of lipofuscin. Sections from a random sample of 20 lymph nodes containing the bodies were submitted to Perl's stain for iron, the periodic acid-Schiff reaction, Schmorl's ferricyanide, and long Ziehl-Neelsen 
Table 2 Relation of yellow bodies to disease: individuals studied are classified according to principal cause of death

\begin{tabular}{|c|c|c|c|c|c|}
\hline \multirow[t]{2}{*}{ Cause of death } & \multicolumn{2}{|c|}{ Individuals } & \multicolumn{3}{|c|}{ Lymph nodes } \\
\hline & No. & No. with YBs & No. & No. with YBs & Per cent with YBs \\
\hline $\begin{array}{l}\text { Myocardial infarction } \\
\text { Cerebral haemorrhage } \\
\text { Chronic rheumatic heart disease } \\
\text { Calcific aortic stenosis } \\
\text { (congenital bicuspid valve) }\end{array}$ & $\begin{array}{l}9 \\
3 \\
2 \\
3\end{array}$ & $\begin{array}{l}3 \\
1 \\
0 \\
2\end{array}$ & $\begin{array}{l}69 \\
23 \\
16 \\
24\end{array}$ & $\begin{array}{r}18 \\
3 \\
0 \\
5\end{array}$ & $\begin{array}{c}26 \cdot 1 \\
13 \cdot 0 \\
0 \\
20 \cdot 8\end{array}$ \\
\hline $\begin{array}{l}\text { Carcinomatosis } \\
\text { Chronic bronchitis and emphysema } \\
\text { Acute respiratory infection } \\
\text { Peptic ulceration } \\
\text { Trauma } \\
\text { Miscellaneous }\end{array}$ & $\begin{array}{l}5 \\
2 \\
5 \\
2 \\
6 \\
9\end{array}$ & $\begin{array}{l}2 \\
1 \\
3 \\
1 \\
3 \\
5\end{array}$ & $\begin{array}{l}38 \\
16 \\
40 \\
16 \\
47 \\
70\end{array}$ & $\begin{array}{r}10 \\
1 \\
7 \\
1 \\
15 \\
22\end{array}$ & $\begin{array}{r}26 \cdot 3 \\
6 \cdot 3 \\
17 \cdot 5 \\
6 \cdot 3 \\
31 \cdot 9 \\
31 \cdot 4\end{array}$ \\
\hline Totals & 46 & 21 & 359 & 82 & $22 \cdot 8$ \\
\hline
\end{tabular}

YB $=$ yellow body

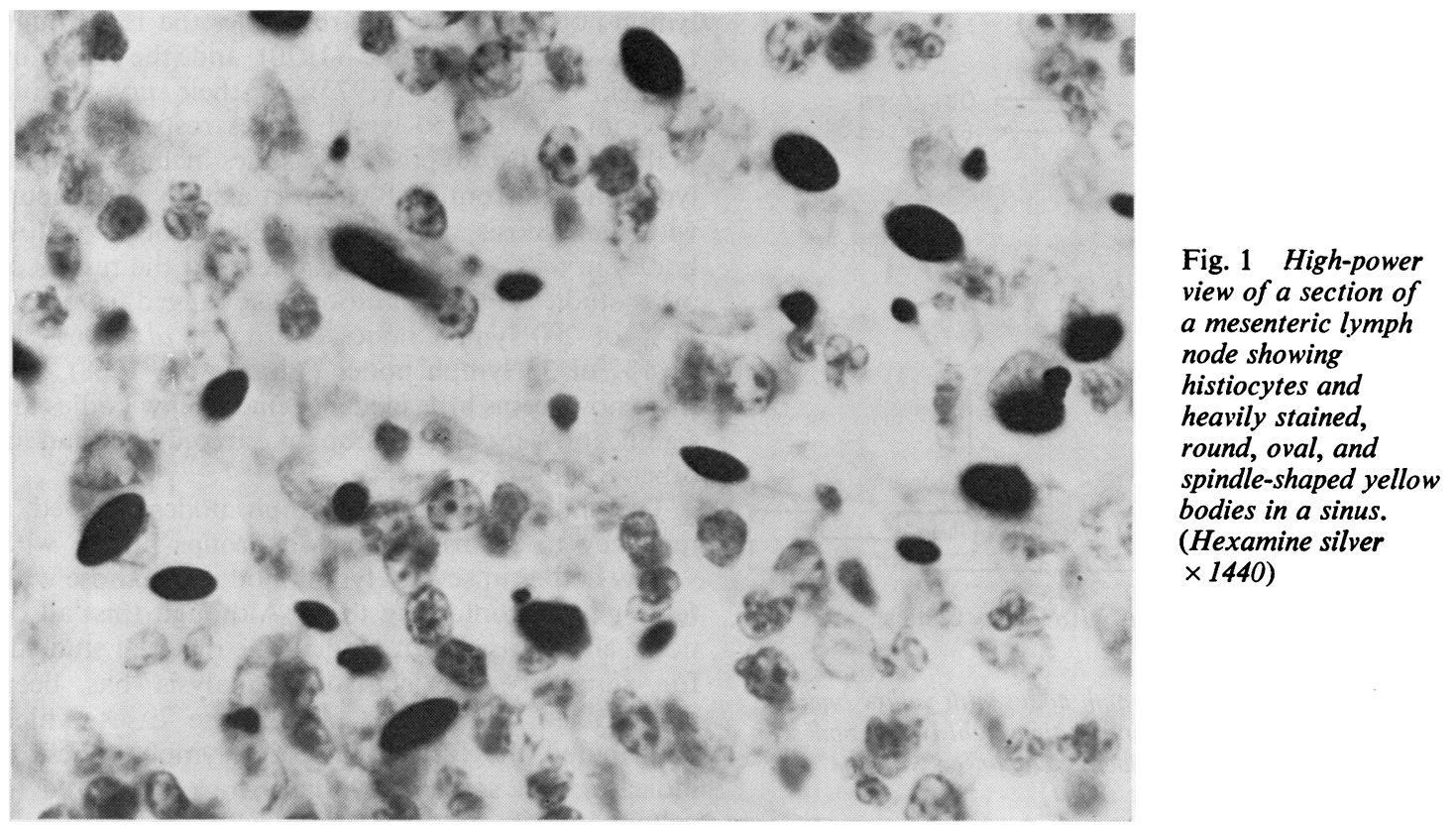

stains and examined for autofluorescence (Zeiss research microscope BG38 UG1 Barrier filter 41).

\section{Results}

Yellow bodies were found in $22.8 \%$ of the 359 lymph nodes examined (Table 1). In most cases they were present in small clusters within the sinuses but in a few examples they were present in large numbers. Their sizes varied from the defined $2 \mu \mathrm{m}$ to $10 \mu \mathrm{m}$ in length. Most reduced hexamine silver. The samples submitted to further stains were uniformly negative to Perl's stain, reduced Schmorl's ferricyanide, and were autofluorescent. Most were PAS-positive and a few weakly acid-fast. The results in individual lymph nodes have not been recorded as these properties varied even between yellow bodies in the same lymph node. The reactions confirmed that the identified structures were histochemically similar to lipofuscin, as was described by Doyle et al. (1973).

Yellow bodies were found in 21 of the $46(45.7 \%)$ cases studied, their ages ranging from 11 to 82 years. They were present in 36 of 185 nodes $(19.5 \%)$ from those aged under 70 years compared with 46 of 174 $(26.4 \%)$ from those aged 70 years or more, and neither this nor any other combination of age groups showed any significant difference. Of 200 nodes from males, $39(19 \cdot 5 \%)$ contained them 
compared with 43 of $159(27.0 \%)$ from females. This difference was not significant. No significant relation between the presence of yellow bodies and any specific disease emerged (Table 2). Nevertheless, the lymph nodes containing yellow bodies were unevenly distributed between cases. According to an expected binomial distribution most of the 37 cases contributing the full set of eight lymph nodes would have between one and three that contained yellow bodies. It was found that the majority came outside this range (Fig. 2), tending to fall into one of two groups with either high or low numbers of affected lymph nodes. The difference between the expected and observed distribution is highly significant $\left(\chi_{3}^{\frac{2}{3}} \mathrm{P}<0.001\right)$.

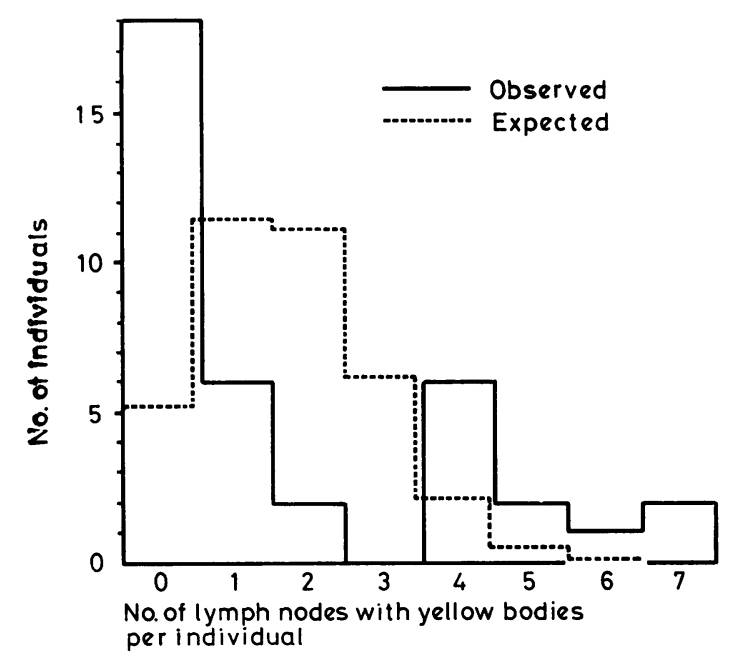

Fig. 2 Distribution of lymph nodes with yellow bodies between 37 cases, each contributing eight lymph nodes. Observed 'all or none' tendency compared with the expected distribution $(\mathrm{P}<0.001)$

Within the separate lymph node groups, the proportion of lymph nodes with yellow bodies ranged from $35.6 \%$ in the mesenteric to $11.1 \%$ in the mediastinal groups (Table 1). The difference between individual groups is not significant. Superficial and deep lymph nodes have characteristic differences in structure (Denz, 1947) and form natural groups for comparison; yellow bodies were found in 15 of $92(16.3 \%)$ superficial lymph nodes (axillary and inguinal groups combined) compared with 62 of $222(27.9 \%$ ) deep lymph nodes (intra-abdominal groups combined), a difference that is just significant $\left(\chi_{1}^{2} \mathrm{P}<0.05\right)$.

\section{Discussion}

The number of yellow bodies found in this survey probably underestimates their true prevalence since rather strict morphological criteria were employed to avoid confusion with large granules of lipofuscin. In a number of lymph nodes, spindleshaped bodies that were clearly visible only on hexamine silver stain were discounted. In addition, scanty yellow bodies may have been missed, particularly in the mediastinal lymph nodes in which heavy carbon pigmentation sometimes made screening difficult.

Previous reports on the prevalence of yellow bodies have been mainly on lymph nodes removed at biopsy, many from patients with sarcoidosis. The identification of yellow bodies in $22.8 \%$ of all lymph nodes in this series resembles the $15 \%$ found by Boyd and Valentine (1970) and the $20 \%$ by Sieracki and Fisher (1973) in their non-sarcoid series of 246 and 50 lymph nodes respectively. As in the present study, the latter series included several lymph nodes from each case. In a study of patients with sarcoidosis, Wesenberg (1966) found yellow bodies in $68 \%$ of 97 lymph nodes, but the results of other studies of this condition have ranged from only $11 \%$ of 200 lymph nodes (Carter et al., 1969) to $31.4 \%$ of 35 lymph nodes (Vira et al., 1968), and there now seems little evidence that yellow bodies are significantly more common in sarcoidosis than in other conditions.

The individual sets of lymph nodes showed a tendency to polarise into two groups-those with yellow bodies in several lymph nodes and those with few or none containing them. Although this 'all or none' effect was apparent in all the material studied, for simplicity the statistical analysis has been confined to the results from those cases which contributed the full set of eight lymph nodes. It indicates that some individuals are predisposed to yellow bodies and that those who are frequently possess them at several sites. However, the basis for this individual variation is not evident from the present study. No relation between the presence of bodies and age or sex has been demonstrated and there is no apparent link with any particular disease. In fact, the bodies were found in two previously well individuals who died after accidental injury, in one of whom they were found in six of the eight lymph nodes examined.

Yellow bodies are probably giant residual bodies developing as excessive accumulations of undigested or indigestible material in activated histiocytic lysosomes (Doyle et al., 1973). The nature or quantity of material phagocytosed by histiocytes could influence their formation. The relatively high 
numbers of bodies in the abdominal lymph nodes of this study suggest that local conditions at these sites favour their development, and the high lipid content of these nodes is a possible factor. Hamazaki (1938) suggested that the presence of the yellow bodies he found in peritoneal lymph nodes might be related to a lipid-rich lymph flow, and Doyle et al. (1973) thought that the bodies might represent undigested phospholipid. The possibility of a quantitative relationship between lipid present within lymph nodes and the formation of yellow bodies deserves further investigation.

Yellow bodies are common in superficial and deep lymph nodes. This study has shown that individual predisposition to them varies but the cause of this variation and the significance of the bodies are yet to be established.

I am indebted to Dr J. D. Davies for advice during the course of this work and for helpful criticism of the manuscript.

\section{References}

Boyd, J. F., and Valentine, J. C. (1970). Unidentified yellow bodies in human lymph-nodes. Journal of Pathology, 102, 58-60.

Carter, C. J., Gross, M. A., and Johnson, F. B. (1969). The selective staining of curious bodies in lymph nodes of patients as a means for diagnosis of sarcoid. Stain Technology, 44, 1-4.
Denz, F. A. (1947). Age changes in lymph nodes. Journal of Pathology and Bacteriology, 59, 575-591.

Doyle, W. F., Brahman, H. D., and Burgess, J. H. (1973). The nature of yellow-brown bodies in peritoneal lymph nodes. Histochemical and electron microscopic evaluation of these bodies in a case of suspected sarcoidosis. Archives of Pathology, 96, 320-326.

Drury, R. A. B., and Wallington, E. A., eds. (1967). Carleton's Histological Technique, 4th edition, p. 229. Oxford University Press, London.

Hall, M., and Eusebi, V. (1978). Yellow-brown spindle bodies in mesenteric lymph nodes: a possible relationship with melanosis coli. Histopathology, 2, 47-52.

Hamazaki, Y. (1938). Über ein neues, saürefeste Substanz führendes Spindelkörperchen der menschlichen Lymphdrüsen. Virchows Archiv für pathologische Anatomie und Physiologie, 301, 490-522.

Sieracki, J. C., and Fisher, E. R. (1973). The ceroid nature of the so-called 'Hamazaki-Wesenberg bodies.' American Journal of Clinical Patholygy, 59, 248-253.

Vira, B., Rosenberg, M. Z., and Meyer, J., II (1968). Spindle-shaped, yeast-like, acid-fast structures in lymph nodes (Abstract). American Journal of Clinical Pathology, 49, 254-255.

Wesenberg, W. (1966). Über säurefeste 'Spindelkörper Hamazaki' bei Sarkoidose der Lymphknoten und über doppellichtbrechende Zelleinschlüsse bei Sarkoidose der Lungen. Archiv für klinische und experimentelle Dermatologie, 227, 101-107.

Requests for reprints to: Dr A. J. C. Tudway, Department of Pathology, University of Bristol Medical School, University Walk, Bristol BS8 1TD, UK. 